\title{
A USURPAÇÃO DOS DIREITOS DO GÊNERO FEMININO NA OBRA LITERÁRIA VOX $^{1}$
}

José Wilson de Oliveira Batista - UNIFSA ${ }^{2}$

Rosália Maria Carvalho Mourão - UNIFSA ${ }^{3}$

\section{RESUMO}

O Direito como fenômeno social utiliza-se interdisciplinarmente da Literatura para discutir as relações humanas de diferentes épocas. A violência contra a mulher, denunciada pelos movimentos feministas, é ocasionada por uma sociedade patriarcal que cria uma ideologia de superioridade de gênero do homem em relação à mulher e uma necropolítica do Estado responsável em dizer quem deve viver ou morrer para ter uma sociedade segura. Além da remoção dos direitos da mulher, o modelo patriarcal contribui para a acrescente caso de feminícidio. O Estado como instituição surgida a partir das necessidades de um grupo para manter a ordem social, tem um papel de resguardar e garantir o exercício dos direitos das mulheres, assim como, evitar qualquer ato que viole a sua liberdade. Verifica-se a importância da Literatura como instrumento que possa ser usado na formação de conscientização em discutir a violência sofrida pela mulher e possa contribuir para o desenvolvimento de uma realidade justa. Este trabalho tem como objetivo verificar a violência contra a mulher por meio da obra literária Vox, de Christina Dalcher (2018) com auxílio do Direito. O método empregado inicia-se através de levantamento de publicações no idioma português, em bases indexadas de revista científica, livros e revista científica com a utilização de fichamento de resumo elaborado pelo pesquisador, ao conter as principais ideias apresentadas em cada material selecionado.

Palavras-Chave:Literatura. Violência. Mulher

\section{INTRODUÇÃO}

Esta publicação discute sobre a violência contra a mulher baseada na obra literária Vox, de Christina Dalcher (2018), trabalhando de maneira interdisciplinar com o Direito e a Literatura. Encontram-se diversas obras que podem ser apresentadas para o Direito como

\footnotetext{
${ }^{1}$ Trabalho apresentado no Congresso Brasileiro Ciência e Sociedade (CBCS 2019), promovido pelo Centro Universitário Santo Agostinho, de 03 a 05 de outubro de 2019, em Teresina-PI.

${ }^{2}$ Graduação em Psicologia pela Universidade Estadual do Piauí (2017). Graduando pelo Centro Universitário Santo Agostinho. E-mail: wilson_the@hotmail.com

${ }^{3}$ Doutoranda em Ciências Criminais - DINTER UNIFSA/PUCRS. Graduação em Licenciatura Plena em Letras pela Universidade Federal do Piauí (1999), graduação em Direito pelo Instituto Camillo Filho (2006) e mestrado em Letras pela Universidade Federal do Piauí (2007). Atualmente é professora do Centro Universitário Faculdade Santo Agostinho. Experiência na área de Letras, com ênfase em Literatura, atuando principalmente nos seguintes temas: literatura infantil, literatura brasileira, direito e literatura, erotismo, avaliação de redação do vestibular. No curso de Direito ministra aulas nas disciplinas de Argumentação Jurídica, Hermenêutica Jurídica, Direito de Família, Estatuto da Criança e do Adolescente e Direito e Literatura. E-mail: rrosapi@ yahoo.com.br 


\section{conweESSOC CIENCIAESOCIEDADE

forma de discutir temas relevantes para a conscientização e combate da violação aos direitos das mulheres em diversos contextos.

No livro Vox da autora Dalcher (2018), o Estado decreta que todas as mulheres não podem falar mais de 100 (cem) palavras por dia, estas são medidas por um contador preso em seu pulso. Caso alguma mulher ultrapasse a quantidade definida, o contador liberará um nível de choque para impedir que a mulher continue a falar. Além disso, o Estado revoga os direitos das mulheres, inclusive os direitos trabalhistas, e impõem obrigações voltadas apenas para a atividade doméstica, enquanto os homens podem exercer qualquer trabalho fora de casa. Para ter um resultado definitivo para censurar a fala feminina, o poder público investe em pesquisa neurolinguística para impedir que as mulheres falem. Não satisfeita com tais medidas que vem sofrendo, Jeans luta pela liberdade dos direitos femininos que foram revogados para que sejam restabelecidos pelo governo de seu país.

A sociedade patriarcal ao definir somente o homem como único ser detentor de direitos é o modelo social responsável pela violência que a mulher vem sofrendo ao longo dos tempos na sociedade como é apresentado na literatura em análise. Entretanto, surgem os movimentos feministas contrários a este modelo de sociedade ao denunciarem as práticas violentas cometidas pelos homens sobre as mulheres. O feminismo exige romper com conceitos que determinam em situar a mulher na condição de submissão da figura masculina (GOMES, 2018).

O Direito como fenômeno social reconhece a mulher como ser humano que tem direito assegurados e garantidos em normas constitucionais e infraconstitucionais para a realização de seus atos que devem ser respeitados por todos. O Estado como instituição criadora de normas jurídicas é também responsável como garantidor de proteção aos direitos da mulher e ofertar meios para que os direitos delas não sejam violados, devido sua condição de gênero. (FERNANDES; CAMPOS; MARASCHIN, 2009)

\section{METODOLOGIA}

Consiste no levantamento de publicações em busca de bases de dados como Scientific Electronic Library Online (SCIELO). Os descritores utilizados e com suas 


\section{CONGBESSO CIENCIAESOCIEDADE Inovação, Diversidaale e Sustentahililitade}

combinações: "Violência contra mulher", "Direito", "Literatura". A partir dos materiais localizados, foi realizada a leitura de resumos e realizando a seleção das publicações corresponde ao tema. Além de base indexada, foram utilizados livros, revistas científicas, dissertações. Foi realizado fichamento e arquivamento dos materiais. A análise e a interpretação dos dados foram realizadas de maneira descritiva para compreensão sobre o tema pesquisado. A pesquisa é de caráter qualitativo, forma descritiva, possibilitando descrever e classificar os dados, com o intuito de reunir o conhecimento produzido sobre o tema explorado na revisão.

\section{RESULTADOS E DISCUSSÃO}

A Literatura é um fenômeno social que tem como característica elementos textuais que demonstram como as relações humanas são diversificadas. Com essa variedade de elementos, o Direito apropria-se da Literatura para facilitar a compreensão dos termos jurídicos para o iniciante acadêmico e ajudar a romper à ideia que o Direito está restritamente condicionados a conceitos formais oriundos de base tradicional da filosofia positiva na resolução dos problemas quando for acionado. Outra contribuição importante sobre a relação dialética entre Direito e Literatura, pode contribuir para o desenvolvimento um senso crítico e reflexivo dos acontecimentos da própria realidade. (FERNANDES; CAMPOS; MARASCHIN, 2009; LIMA; CHAVES, 2011).

O Direito é formado por um conjunto sistemático de normas jurídicas elaboradas por diversos profissionais da área com o intuito de tornar a convivência mais pacífica ao obedecer a regras e normas jurídicas, a Literatura utiliza-se de elementos textuais com objetivo de narrar acontecimentos que fazem parte de uma determinada realidade, sem a obrigação de ser fiel a esta, mas com o intuito de promover discussões e amplos debates sobre os mais variados temas. Na dialética entre Direito e Literatura é possível realizar diversas pesquisas mensuráveis para compreender e praticar as técnicas jurídicas para contribuir na formação profissional. (RUIZ; RIBEIRO, 2017).

Em Vox, o Estado revoga arbitrariamente diversos direitos das mulheres. Além de limitar a quantidade de palavras diariamente das mulheres, elas são impedidas de exercer 


\section{CONGERSSOC CIENCIAESOCIEDADE

uma profissão, não podem sair de casa sem a presença do marido, remoção do direito em participar das eleições e não podem manifestar sua sexualidade homoafetiva. Caso a mulher manifeste sua sexualidade diferente ao modelo heterossexual, elas sofrem várias ações de violências físicas principalmente pelo poder público que deveria protegê-las. Com relação as mulheres heterossexuais, a relação sexual somente é permitida durante o casamento. Entretanto, caso a mulher tenha algum envolvimento sexual fora do casamento ou durante o namoro, elas são severamente penalizadas porque esta prática é totalmente proibida.

A violência sofrida pela mulher é epistemologicamente compreendida pela junção de dois elementos: o patriarcal e a necropolítica. O primeiro elemento é definido como uma forma de estrutura social que realiza a hierarquia de pensamento de dominação dos homens sobre as mulheres em diferentes contextos sociais, seja no meio familiar, nas relações interpessoais quanto no ambiente de trabalho. Essa valorização voltada apenas para a figura do homem cria uma estrutura de violência, de desigualdade para a mulher, que passa a não ser questionada. A necropolítica consiste na violência praticada pelo poder público estatal ao exercer o direito de distinguir os sujeitos que merecem a morte em relação sobre aqueles que têm o direito de viver, independe da condição social (GOMES, 2018; MBEMBE, 2018).

Dentro da obra literária Vox, a sociedade patriarcal e a necropolítica estão presentes em diversas passagens da história como, por exemplo, somente o homem pode exercer atividades fora de casa, enquanto a mulher é responsável apenas para atividades domésticas. Este modelo de sociedade patriarcal é sustentado por um Estado que é capaz de matar aquelas que ousarem "desvirtuar" a ideologia dominante masculina. A morte citada não se refere apenas à questão na extinção da vida do corpo, mas a morte civil no tocante a liberdade da fala, a liberdade de escolha que o Estado não permite à mulher exercer na obra apresentada.

No artigo 5o da Constituição brasileira é assegurada a igualdade entre homens e mulheres sem fazer nenhuma distinção. Outra conquista dentro da Carta Magna, não se admite que direito à vida, à liberdade, à igualdade, à segurança e à propriedade, e dentre outros direitos ao longo da constituição sejam violados. A proteção dos direitos compete ao 


\section{conghESSO CIENCIAESOCIEDADE

Estado Democrático Livre de Direito garantir e proteger os interesses individuais das pessoas e coletividade (BRASIL, 1988; MASSON, 2018).

Diante de tamanha violência que a mulher vem sofrendo ao longo dos tempos, foram criados vários serviços, instituições e normas para proteção dela. A preocupação inicial voltada para fazer frente à violência contra a mulher deu-se por meio de movimento feminista iniciada nos anos 70 ao denunciarem vários casos de assassinatos de mulheres por uma sociedade patriarcal que intitula a mulher como ser inferior, removendo a sua humanidade. A mulher sofre vários tipos de violência, mas o que causa grande revolta é que as violências são realizadas por pessoas que têm algum vínculo afetivo com estas vítimas, mas ocorre que os agentes do poder público estatal também cometem violência contra a mulher quando ela busca por ajuda devido à violência sofrida e não é bem acolhida nas delegacias da mulher, no IML e na defensoria pública (SCHRAIBER et al., 2002; GOMES, 2018).

Conceição (2012) apresenta o conceito sobre feminicídio quando uma mulher é vítima de homicídio simplesmente pelo fato de ser do sexo feminino. Além desta definição são apresentadas três situações para ser denominado feminicídio: quando entre a vítima e o agressor há alguma relação íntima de afeto ou existe um vínculo de parentesco; ocorre a prática de qualquer violência sexual contra a vítima ao ponto que pode ocasionar alguma mutilação; ou pela atitude bárbara do agressor quando ocasiona a desfiguração ou mata a mulher simplesmente devido ao seu gênero feminino. Para Lei $\mathrm{n}^{\circ} 13.104$, feminicídio é apresentado no art. 121, § 2-A, considera-se que há razões de condição de sexo feminino quando o crime envolve: I - violência doméstica e familiar; II - menosprezo ou discriminação à condição de mulher (BRASIL, 2015).

De acordo com Gomes (2013), o homem ao realizar uma ação de violência contra uma mulher é por ele não ter habilidades em aceitar que a mulher é um ser humano que vive no processo de transformação. Esta transformação de gênero feminino dentro de uma sociedade patriarcal tem exclusivamente como objetivo de conquistar novos espaços que outrora são definidos apenas para os homens. Além disso, este mesmo homem violento não 


\section{conweESSOOCIENCIAESOCIEDADE

está preparado em aceitar que a liberdade da mulher pode levá-la a grandes conquistas sociais sem precisar da figura masculina.

A violência é um comportamento agressivo praticado espontaneamente pelo agente que tem como determinada finalidade em destruir aquilo de mais precioso, a liberdade de viver de outra pessoa. Essa atitude do agressor viola os preceitos éticos não aceitos dentro de uma sociedade de direito na qual reconhece a humanidade com caráter essencial da liberdade de todas as pessoas em sua totalidade. Como este ato é praticado pelo próprio agente, então é necessário que sofras as devidas consequências estabelecidas na norma jurídica devido sua atitude (BENTES; SOARES, 2018).

Uma pesquisa realizada em diversas Delegacias Especializadas de Atendimento à Mulher no Estado do Rio de Janeiro apresenta informações de mulheres que realizam o registro de algum de tipo de violência. A maior parte de registros demonstra que mulheres na faixa etária entre 14 a 45 anos, exercem alguma atividade fora de casa, sem vínculo matrimonial, com baixa escolaridade, são financeiramente dependentes e a agressão ocorreu principalmente dentro da residência. Perante a discussão dos dados levantados, verificou-se haver poucos registros de denúncia de violência sofrida por mulheres financeiramente independentes, com alta escolaridade e casadas. Entretanto, devido a estes baixos índices de registro, não garante que estas mulheres não sofram algum tipo de violência. Os motivos de poucos registros podem ser que a vítima sofra a intimidação e ameaça do agressor ou por elas sentirem constrangidas, culpadas e envergonhadas ao relatar a violência sofrida (SCHRAIBER et al., 2002; MOURA; ALBUQUERQUE NETO; SOUZA, 2012).

A partir do momento que qualquer pessoa nasce com vida, ela adquire personalidade jurídica que tem os direitos e deveres assegurados dentro do ordenamento jurídico brasileiro, denominada pessoa natural. Esses direitos como a vida, integridade física, liberdade e dentre outras são apenas exemplificativos da pessoa natural, são de caráter cuja função é de proteção dos valores fundamentais da dignidade da pessoa humana (GONÇALVES, 2016; GAGLIANO, PAMPLONA FILHO, 2018). Esses direitos também são assegurados à mulher assim que ela nasce, no entanto, o que se verifica é que muitos 


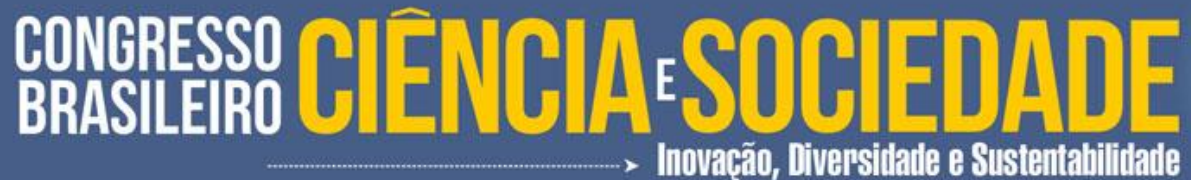

direitos da personalidade são violados constantemente, sem que o Poder Público consiga dá uma resposta efetiva às mulheres que são massacradas onde deveriam se sentir mais segura, o próprio lar.

O Estado como uma instituição criada por um grupo de pessoas para atender as suas necessidades, cujo poder legitimado é o reconhecimento pela maioria da população, tem um papel de resguardar o interesse coletivo, e encontrar dentro de sua própria organização institucional uma solução que produza resultados benéficos para alcançar os diversos contextos sociais responsáveis pela sua gênese (DALLARI, 2016). Para isso, o Estado brasileiro elaborou leis como 11.340/06 (Lei Maria da Penha) e Lei 13.104/15 (Lei do Feminicídio) para tentar reverter esta situação de violência e proteger as mulheres (BRASIL, 2006; BRASIL, 2015).

O Estado tem o dever de responsabilidade na preservação da ordem pública e na proteção a pessoas tanto a níveis de elementos patrimoniais quanto extrapatrimoniais por meios de seus órgãos competentes, com auxílio de seus agentes tecnicamente capazes. 0 Estado configura-se o grande responsável ao oferecimento de segurança para aqueles que se encontra em situação de vulnerabilidade ocasionado pela violência. Entretanto, é necessário reforçar não se pode esperar somente a atuação do Estado na proteção, mas compete a qualquer indivíduo a incumbência de acionar esta instituição ao perceber alguma violência sofrida pela mulher, pois com essa atitude conjunta contribui para fortalecimento do bem social (FREIRE, 2009; GOMES, 2018).

Apesar das leis para proteger as mulheres, o que se observa é um aumento expressivo do número de casos de agressões físicas, psicológicas, morais, patrimoniais, feminicídios. Para isso basta ler ou assistir diariamente os jornais, pode-se dizer que a cifra negra (números de casos de violência que não eram relatados) diminuiu, porque as mulheres estão mais conscientes de seus direitos, mas também não houve uma discussão aprofundada na sociedade sobre a questão do machismo, patriarcado, desigualdade de gênero. Alguns homens continuam acreditando que as mulheres são propriedades deles, que eles decidem tudo, que têm poder de vida e morte sobre elas. Faz-se necessário uma conscientização e uma educação que envolva discussão a respeito de gênero, para promover uma sociedade livre, justa e solidária como apregoa a Constituição Federal. 


\section{conghESSO CIENCIAESOCIEDADE \\ -}

\section{CONSIDERAÇÕES FINAIS/CONCLUSÕES}

A Literatura é um fenômeno social diversificado que apresenta as características de uma determinada sociedade. Na obra Vox de Chistina Dalcher, demonstra-se que a Literatura serve também como um importante instrumento voltado para combater a violência contra a mulher ao utilizar uma obra literária como forma de promover a discussão e reflexão a respeito do tema.

O Estado Democrático Livre de Direito é uma organização comprometida em resguardar e proteger com auxílios de outras instituições os direitos das mulheres. Uma instituição pública que utiliza as normas jurídicas a favor das mulheres contribui para a formação de uma sociedade instrumentalizada na justiça e igualitária.

O homem responsável pela violência que a mulher vem sofrendo ao longo dos anos tem concepção naturalizante mergulha no modelo patriarcal ao determinar a superioridade da figura masculina em relação à feminina. Esse modelo social impede a mulher de exercer seus direitos em diversos contextos seja na família, no trabalho e nas relações afetivas, mas devido aos movimentos feministas, confundidos como problemas sociais, são grandes responsáveis na contribuição em romper com um modelo patriarcal ao coisificar o gênero feminino.

\section{REFERÊNCIAS}

BENTES, H. H. S.; SOARES. J. V. Violência contra as mulheres como transgressão da ética: análise de não as matem, de Lima Barreto. In: COLÓQUIO INTERNACIONAL DE DIREITO E LITERATURA, 6, 2018, Porto Alegre. Anais... Porto Alegre: RDL, 2018. Disponível em:<http://rdl.org.br/seer/index.php/anacidil/article/view/391/pdf>. Acesso em: 06 jan. 2019.

BRASIL. Lei no 11.340, de 07 de agosto de 2006. Brasília, DF, 07 ago. 2006. Disponível em:<http://www.planalto.gov.br/ccivil_03/_Ato2004-2006/2006/Lei/L11340.htm>. Acesso em: 15 fev. 2019. 


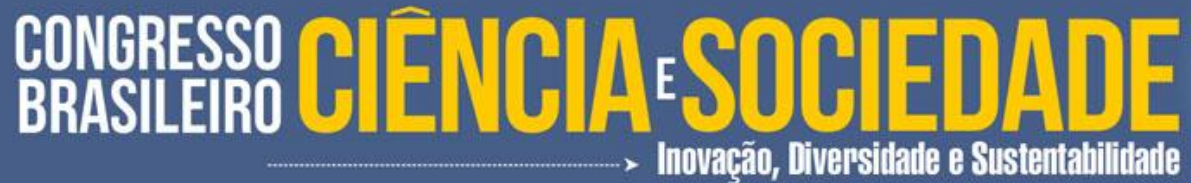

BRASIL. Lei no. 13.104, de 09 de março de 2015. Brasília, DF, 09 mar. 2015. Disponível em: <http://www.planalto.gov.br/ccivil_03/_Ato2015-2018/2015/Lei/L13104.htm>. Acesso em: 10 jan. 2019.

BRASIL. Constituição (1988). Constituição da República Federativa do Brasil. Brasília, DF, 05 out. 1988. Disponível em:

<http://www.planalto.gov.br/ccivil_03/constituicao/constituicaocompilado.htm>. Acesso em: 26 jan. 2019.

CONCEIÇÃO, E. B. L. Feminicídio no brasil. 2012. Disponível em:

<http://www.facnopar.com.br/conteudo-arquivos/arquivo-2017-06-14-

14974728811632.pdf>. Acesso em: 21 de jan. 2019.

DALCHER, C. Vox. São Paulo: Arqueiro, 2018.

DALLARI, D. A. Elementos de teoria geral do Estado. 33. ed. São Paulo: Saraiva, 2016.

FERNANDES, C. D.; CAMPOS, K. M.; MARASCHIN, C. Direito e Literatura: uma análise interdisciplinar do fenômeno jurídico a partir dos textos literários. Revista Anagram, ano 2, São Paulo, jul-ago, 2009. Disponível em:

<http://www.revistas.usp.br/anagrama/article/view/35382/38102>. Acesso em: 06 jan. 2019.

FREIRE, M. D. Paradigmas de Segurança no Brasil: da Ditadura aos nossos dias. Aurora, ano 3, n.5, dez. 2009. Disponível em:

<http://www2.marilia.unesp.br/revistas/index.php/aurora/article/view/1219/1086>. Acesso em: 04 jan. 2019.

GAGLIANO, P. S.; PAMPLONA FILHO, R. Novo curso de direito civil, volume 1: parte geral. 20. ed. São Paulo: Saraiva, 2018.

GOMES, C. M. Marcas da violência contra a mulher na literatura. Revista Diadorim. v.13. Rio de Janeiro. 2013. Disponível em: <https://ri.ufs.br/bitstream/riufs/1961/1/MarcasViolenciaMulher.pdf>. Acesso em: 06 jan. 2019.

GOMES, I. S. Feminicídios: um longo debate. Rev. Estud. Fem. v.26, n.2, 


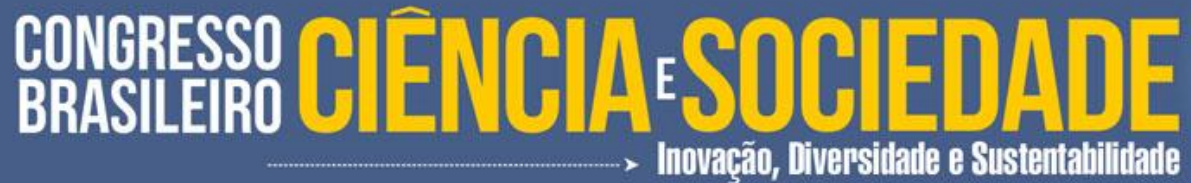

2018. Disponível em: <http://www.scielo.br/pdf/ref/v26n2/1806-9584-ref-26-02e39651.pdf>. Acesso em: 07 jan. 2019.

GONÇALVES, C. R. Direito civil brasileiro, volume 1: Parte Geral. 16. ed. São Paulo: Saraiva, 2016.

LIMA, C. S. S.; CHAVES, G. R. G. Dom casmurro de Machado de Assis: uma interface entre direito e literatura. Revista Ética e Filosofia Política. v. 12, n. 14. out., 2011. Disponível em: <http://www.ufjf.br/eticaefilosofia/files/2011/10/14_2_lima_chaves_10.pdf >. Acesso em: 05 jan. 2019.

MASSON, N. Manual de Direito Constitucional. ed. 6. Salvador: JusPudivm. 2018.

MBEMBE. A. Necropolítica: Biopoder, soberania, estado de exceção, política da morte. ed. 3. São Paulo: n-1 edições, 2018.

MourA, M. A. V.; ALBUQUerque NeTO, L.; SOUZA, M. H. N. Perfil sociodemográfico de mulheres em situação de violência assistidas nas delegacias especializadas. Esc Anna Nery. v. 3. n. 16, jut-set, 2012. Disponível em: <https://www.redalyc.org/pdf/1277/127723305002.pdf>. Acesso em: 32 jan. 2019.

RUIZ, P. A. F.; RIBEIRO, I. A. Produção científica em direito e literatura no brasil. In: COLÓQUIO INTERNACIONAL DE DIREITO E LITERATURA, 6, 2017, Porto Alegre. Anais... Porto Alegre: RDL, 2017. Disponível em: <http://rdl.org.br/seer/index.php/anacidil/article/view/327/pdf>. Acesso em: 23 jan. 2019.

SCHRAIBER , L. B. et al. Violência contra a mulher: estudo em uma unidade de atenção primária à saúde. Rev Saúde Pública. v. 3, n.36, 2002. Disponível em: <https://www.scielosp.org/pdf/rsp/2002.v36n4/470-477/pt>. Acesso em: 24 jan. 2019 